\title{
Piso salarial nacional no plano de carreira do magistério público do município de Teresina ${ }^{1}$
}

\author{
Luís Carlos Sales ${ }^{2}$ \\ lwis2006@gmail.com
}

\begin{abstract}
Resumo
Neste artigo são analisados o impacto da Lei do Piso no Plano de Carreira do Magistério Público do Município de Teresina de 2001 e a saída encontrada pelo município para se adequar à Lei do Piso. São feitas breves teorizações sobre Salário e Planos de Carreira. As características do Plano de 2001 são confrontadas com as do plano de 1986. É aplicado o valor do piso no plano de 2001 e analisado o seu impacto. As despesas com a folha de pagamento cresceriam bastante, preferindo o município adequar o seu plano ao aprovar a Lei ${ }^{0} 3.951 / 2009$. Constatou-se que nem sempre as leis são cumpridas e que pensar numa educação de qualidade sem prever recursos adicionais é simplesmente transferir a responsabilidade para os professores, esperando deles abnegação e sacerdócio. É pensar que todo município brasileiro possui receitas suficientes para pagar bem seus professores. É não perceber que o salário tem sido uma espécie de cabo de guerra, que tem como único perdedor a educação da população.
\end{abstract}

Palavras-chave: financiamento da educação; piso salarial; plano de carreira.

1 Embora a responsabilidade pelo artigo seja do autor, ele contou com contribuições dos pesquisadores: Prof $^{a}$. Dra. Rosana Evangelista da Cruz (UFPI), Prof ${ }^{a}$ Ms. Magna Jovita Gomes de Sales e Silva, Profa. Ms. Maria do Socorro Lages (UFPI), Profa. Esp. Samara de Oliveira Silva e Profa. Esp. Lucineide Maria dos Santos Soares (mestrandas - UFPI e docentes da rede estadual/PI e municipal de Teresina) e Profa. Esp. Silvânia Uchôa de Castro e Profa. Esp. Francislene Santos Castro (Auxiliares de Pesquisa). As bolsistas de iniciação científica: Karen Lane Santos Garcia, Rosimeire Alves Feitosa, Sandra Batista da Silva, Thicyana Mara Veloso e Ana Paula Leal (Pedagogia) também colaboraram com o trabalho.

2 Doutor em Educação pela Universidade Federal do Rio Grande do Norte, Brasil (1999), professor Associado da Universidade Federal do Piauí, Brasil. 


\section{Introdução}

No dia 16 de julho de 2008, o Presidente da República sancionou a Lei $n^{\circ} 11.738$ que regulamenta o piso salarial profissional nacional para os profissionais do magistério público da educação básica, que ficou popularmente conhecida como Lei do Piso. A referida lei gerou expectativas positivas para os profissionais do magistério público, despertou preocupação para muitos gestores e incredulidade por parte dos pesquisadores da área de financiamento da educação.

Neste artigo, serão analisados dois aspectos pontuais: o impacto da Lei do Piso no Plano de Cargos e Salários do Magistério Público da Rede de Ensino do Município de Teresina, em vigor desde 17 de janeiro de 2001 (Lei $n^{\circ} 2.972 / 2001$ ) e a saída encontrada pelo referido município para se adequar às demandas da Lei do Piso, quando aprovou a Lei Complementar $\mathrm{n}^{\circ}$ 3.951, em 17 de dezembro de 2009.

Inicialmente, serão feitas breves considerações teóricas sobre Salário e Planos de Carreira e, em seguida, serão apresentadas resumidamente as características do Plano de Cargos dos Professores do Município de Teresina, também denominado de Estatuto do Magistério (Lei ${ }^{\circ}$ 2.972/2001), confrontando em seguida com o plano anterior, instituído em 02 de dezembro de 1986 (Lei n ${ }^{\circ} 1.870 / 1986$ ). Finalmente, será aplicado o valor do piso no início da carreira do plano em vigor (o de 2001) e analisado o seu impacto acima anunciado.

\section{Considerações teóricas sobre salário e planos de carreira}

É consenso que nas relações entre trabalhador e empregador, historicamente o salário tem sido ponto de desentendimento. "Receber um salário justo, como contrapartida do aluguel da sua força de trabalho foi, e ainda é, uma das bandeiras que o trabalhador busca diariamente com o auxílio sindical" (CASTRO, 2010, p.3). Do lado patronal, é com a redução dos salários que o empregador consegue aumentar sua margem de lucro. Nessa dicotomia de interesses, o plano de cargos e salários é um documento que serve para regulamentar as relações entre trabalhador e empregador, 
deixando transparente para o trabalhador suas regras de ascensão e a política salarial da empresa. Para o lado do empregador, um bom plano de carreira pode traduzir-se em atratividade dos melhores quadros disponíveis no mercado, segundo Morduchowicz (2009), e, sobretudo, poderá estimular a permanência dos melhores talentos na instituição.

Mais do que o salário, o atendimento às necessidades básicas do trabalhador deve prevalecer em qualquer plano de carreira a fim de que o trabalhador possa desempenhar bem suas funções. Para Castro (2010), fazendo referência à teoria de Maslow em relação à questão do salário como fator de motivação, o salário é o pano de fundo para a satisfação das necessidades do trabalhador. É por seu intermédio que o trabalhador tem assegurada a satisfação de suas necessidades básicas, independentes da empresa.

Castro (2010) afirma que Frederick Taylor acreditava poder tornar as fábricas do início do século XX mais produtivas pela simplificação das tarefas e dos movimentos executados pelos empregados, procurando também uma maior especialização de cada funcionário. Segundo essa autora, Taylor não se preocupava com a satisfação que o empregado pudesse ter se executasse um trabalho no qual lhe fosse facultado acompanhar o processo de produção. Além disso,

[...] Com os estudos (final da década de 20, início da de 30), que serviam de base para a "Teoria das Relações Humanas", dentro de uma Abordagem Humanística da Administração, E. Mayo concluiu [...] que o grupo social, dentro da organização informal, afeta profundamente as atitudes dos funcionários. A partir de então, começaram a estudar os fatores que influiriam no processo de motivação dos empregados. Foi percebido que, isoladamente, o salário não é fator de motivação (CASTRO, 2010, p.9).

Embora relativizando sua importância, a autora conclui afirmando que o salário é

uma demonstração objetiva do quanto a empresa valoriza o trabalho de seu funcionário. Associado ao plano de carreira, se bem administrado pelos recursos humanos da empresa, ele pode vir a ser não propriamente um fator de motivação, mas um 
fator que servirá de base aos fatores motivadores ligados ao cargo ocupado, à perspectiva de crescimento profissional e trabalho executado (CASTRO, 2010, p.10).

Após essas rápidas considerações teóricas sobre Salário e Planos de Carreira, na sequência serão apresentadas as características dos dois Planos de Cargos e Salários instituídos pela Prefeitura Municipal de Teresina para atender os professores e pedagogos ${ }^{3}$ da Rede Pública Municipal de Ensino.

\section{O Plano de Cargos e Salários instituído pela Lei ${ }^{\circ} 1.870$ de $02 / 12 / 1986$}

Esse plano organizava os professores em 5 classes (A, B, C, D e E) e fixava em 3 (três) salários mínimos o valor a ser pago ao professor com 20 horas, Classe $\mathrm{A}^{4}$ Nível 1. O professor Classe E, nível 1, portador de Curso de Especialização, deveria receber 4,25 salários mínimos mais 30\% de regência. Cada classe possuía 7 níveis e o professor receberia 10\% na mudança/progressão de um nível inferior para um superior. O interstício da progressão era de 2 anos e a mudança de classe ou promoção estava relacionada com obtenção do título correspondente a cada classe. Como os salários estavam indexados ao salário mínimo, o professor, no último nível da carreira, pelo plano de 1986, deveria receber 9,78 salários mínimos [vencimento $(4,25)$ x nível $7(1,77)+30 \%$ da regência], o que corresponderia em valores atuais (dezembro/2010) a R $\$ 4.987,80$. O valor do maior salário era 2,51 vezes maior que o valor do menor salário.

\section{O Plano de Cargos e Salários instituído pela Lei $n^{0} 2.972$ de 17/01/2001}

Esse plano passou a organizar os professores em 8 classes (A, B, C, D, E, F, G e H) e fixou em $\mathrm{R} \$ 497,90^{5}$ o valor do vencimento mais a

3 Em conformidade com o Plano de Cargos de Salários de 2001, em discussão neste artigo, quando se mencionar a palavra professores, esta ser referirá a professores e pedagogos.

4 Trata-se do professor regularmente investido em cargo para cujo provimento se exija habilitação específica de Segundo Grau, obtida em três séries.

5 Esse valor em salários mínimos da época correspondia: $\mathrm{R} \$ 3,30$. 
regência a ser pago ao professor com 40 horas, Classe A Nível 1, quando da implantação do plano em 2001. O professor Classe “"H", nível 11, 40 horas, deveria receber $\mathrm{R} \$ 2.532,99^{6}$ pelo vencimento mais a regência, sendo exigido desse professor o nível de Pós-doutorado. Cada classe passou a possuir 11 níveis e, toda vez que o professor mudasse de nível, ele receberia $10 \%$ do nível 1 até o nível 7 e $5 \%$ do nível 8 até o nível 11. O interstício de mudança de nível aumentou para 3 anos e a mudança de classe também estava relacionada com a obtenção do título correspondente a cada classe. O valor do maior salário é 5,09 vezes maior que o valor do menor salário.

\section{Comparações entre os Planos de Cargos e Salários do Município de Teresina}

Comparando o plano de 1986 com o plano de 2001, constata-se que o professor, no plano de 1986, com Especialização (Classe E, Nível 7) receberia mais que o professor no plano de 2001. Pelo plano de 1986, receberia 9,78 salários mínimos da época (vencimento + regência) e pelo plano de 2001 receberia 10,37 salários mínimos da época (vencimento + regência), considerando que no plano de 1986 a carga horária do professor era de 20h e no plano de 2001 a carga horária é de 40h (9,78 x $2>10,37)$.

Além disso, o plano de 2001 trouxe perdas para o professor quando se observa que o interstício para a mudança de nível, no plano de 1986, era de apenas 2 anos e, no de 2001, aumentou para 3 anos; ou seja, no plano de 1986, os professores atingiriam o topo da carreira em menos tempo, ou seja, evoluiriam numa carreira mais curta, em 7 níveis, menos que o plano de 2001 com 11 níveis.

Considerando que no plano de 1986 não se previa a titulação de mestres, doutores e pós-doutores (classes F, G e H), o plano de 2001 poderia trazer algumas compensações apenas para aqueles que atingissem tais titulações, uma vez que as classes do plano de 2001 passaram a contemplar até o nível de pós-doutor (Classe H). Ocorre que as titulações de doutor e pós-doutor são de difícil obtenção e,

6 Esse valor em salários mínimos da época correspondia: $R$ \$16,77. 
até dezembro de 2009, a rede contava com apenas um professor com doutorado e nenhum pós-doutor. Portanto, para a maioria dos professores, as classes F, G e H não representaram vantagens efetivas, pois o maior quantitativo de professores situava-se, até dezembro de 2010, nas classes D e E, exigindo-se para essas classes, respectivamente, graduação e especialização. A partir dessas considerações, entende-se que o plano de 2001 não trouxe vantagens efetivas para os professores.

"No papel", conforme o que estava fixado na lei, o plano de 1986 apresentava mais vantagens para os professores, uma vez que os valores correspondentes às classes e aos níveis eram indexados ao salário mínimo, o que garantiria reajustes automáticos aos salários dos professores. No entanto, consultando contracheques de professores com datas anteriores a 2001, constatou-se que a indexação ao salário mínimo era descumprida.

O descumprimento da Lei também ocorria no não atendimento das mudanças de nível. O plano de 2001 foi descumprido no primeiro interstício (3 anos - 17/01/2001 a 17/01/2004). O professor que trabalhou nesses 3 primeiros anos não recebeu sua progressão correspondente. A situação só foi regularizada a partir de agosto de 2006, quando entrou em vigor o Decreto $n^{\circ}$ 6.835/2006, que concedeu progressão por merecimento, automática, em 2006, "aos professores e pedagogos, correspondendo ao interstício de 36 (trinta e seis) meses, contado a partir de 17 de janeiro de 2001" (TERESINA, 2006).

Por que os planos não são atendidos: falta de vontade política ou falta de recursos financeiros?

Quando o gestor de uma secretaria de educação decide (ou é levado a) reformular o plano de cargos e salários dos professores, geralmente toma como ponto de partida o valor da folha de pagamento utilizada pelo plano antigo e admite um crescimento da folha, na passagem do plano velho para o plano novo, motivado pelo inevitável enquadramento dos professores nas novas classes e níveis contemplados no plano que se inicia. No processo de enquadramento, ocorre a elevação da folha, tendo em vista que muitos professores ganham percentuais variáveis com o enquadramento e nenhum professor deve perder, na passagem 
de um plano para outro. Portanto, para a maioria dos gestores, na implantação de um novo plano, a elevação da folha deve levar em conta apenas a despesa com o enquadramento bem como os reajustes definidos anualmente, conforme os índices de inflação.

Não havendo previsão orçamentária para o crescimento natural da folha, que ocorre anualmente em função das mudanças de classe e de nível, as secretarias, nos anos seguintes, não terão como garantir o cumprimento do novo plano. Segundo a Controladoria Geral da União (CGU), "o gestor deve estar atento e planejar devidamente os gastos com os profissionais do magistério, especialmente para a necessidade de se ter um Plano de Carreira atualizado, instituído por meio de lei específica" (BRASIL, 2010, p.30).

Essa falta de planejamento ficou evidente na Prefeitura Municipal de Teresina, na passagem do Plano de 1986 para o Plano de 2001, pois, provavelmente pressionado pela legislação, estimulou a evolução dos professores na carreira (Artigos 46 e 50 do Plano de 20017), sem se dar conta da dimensão de seu impacto na folha.

A seguir, é apresentada uma série histórica, compreendendo os anos de 1996 a 2009, onde se pode observar a movimentação dos professores na carreira, especialmente, a diminuição da quantidade de professores das classes A e B e o crescimento das classes D e E. Vale destacar que a passagem do professor classe A para a classe D (exigência: Licenciatura Plena) representa $36 \%$ de aumento sobre o vencimento salarial do professor. Tal movimentação tornou-se mais acentuada a partir de 2001, como pode ser visto no GRAF. 1, conforme se segue:

\footnotetext{
7 Art. 46. Nos cinco anos seguintes após a publicação desta Lei, a Secretaria Municipal de Educação e Cultura oferecerá condições especiais para que os professores do quadro suplementar se qualifiquem [...]. Art. 50. A Secretaria Municipal de Educação e Cultura tomará providências para que, até o final da década da educação, instituída pela Lei 9.394, de 20.12.96, todos os professores do ensino fundamental tenham qualificação de curso superior.

Nota: Desde 1998, a Prefeitura Municipal de Teresina, através da Secretaria Municipal de Educação e Cultura, em convênio com a Universidade Federal do Piauí e com a Fundação de Apoio ao Ensino, Pesquisa e Extensão (FUNDAPE), vem realizando concurso vestibular em Licenciatura Plena em Pedagogia com Habilitação em Magistério das Séries Iniciais do Ensino Fundamental. (O Art. 50 e a nota acima constam do plano de 2001. O gestor fez questão de registrar, no plano, a política de qualificação do município).
} 


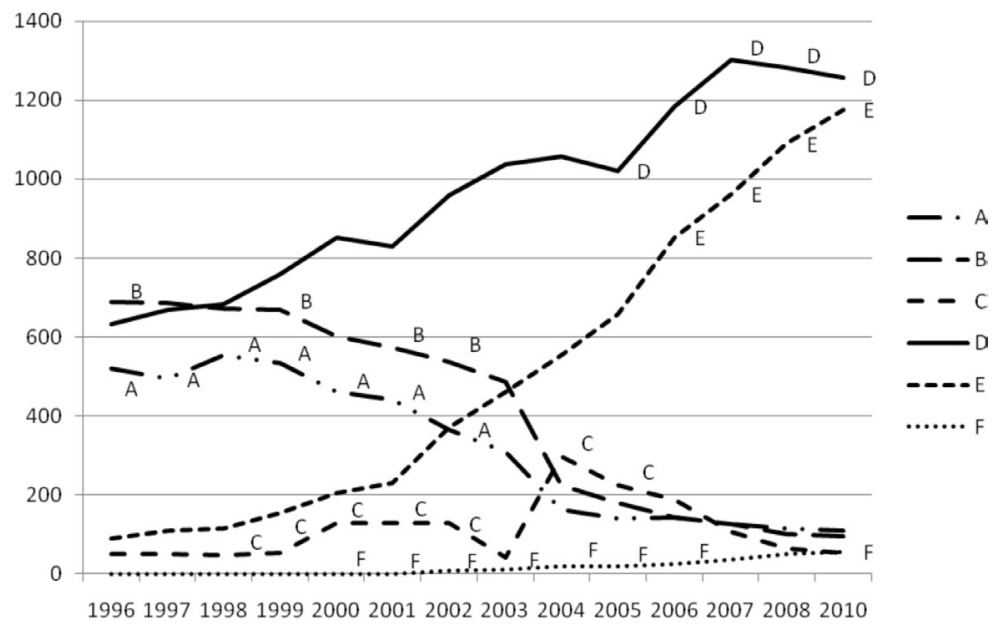

GRÁFICO 1: Evolução das Classes de Professores (1996 - 2009)

Fonte: Secretaria de Municipal de Administração do Município de Teresina.

Essa movimentação na carreira deve levar em consideração a seguinte composição para cada uma das classes: Classe "A" - deve possuir habilitação específica de $2^{\circ} \mathrm{Grau}$, obtida em 3 séries; Classe "B" - deve possuir habilitação específica de $2^{\circ}$ Grau, obtida em 4 séries; Classe "C" - deve possuir habilitação específica de grau superior, em curso de curta duração; Classe "D" - deve possuir habilitação específica de grau superior, em cursos de licenciatura plena; Classe "E" - deve possuir habilitação específica de grau superior e curso específico de especialização; Classe "F" - deve possuir, além de habilitação de grau superior, curso específico de mestrado; Classe "G" - deve possuir, além de habilitação de grau superior, curso específico de doutorado e, por fim, Classe "H" - deve possuir, além de habilitação de grau superior, curso específico de pós-doutorado.

No GRAF. 1, em referência, pode ser observado que, a partir de 2001, as classes de menor salário diminuíram e as classes de maior salário cresceram. Em 2009, a quantidade de professores nas classes A, B e C não passava de 200; contrariamente, os professores das classes D e E ultrapassavam a quantidade de 1.100. Observa-se, portanto, que houve melhoria significativa na titulação dos professores, com impactos 
positivos na qualidade do ensino oferecido pela rede ${ }^{8}$.

A decisão da Prefeitura de financiar a qualificação dos professores em nível de graduação, num primeiro momento, e de financiar cursos de especialização, num segundo momento, foi muito positiva e teve também impacto significativo na movimentação dos professores na direção das classes mais elevadas e, consequentemente, na elevação da folha de pagamento, bem como na elevação da dificuldade para o seu pagamento. A não previsão da referida movimentação revela a fragilidade no planejamento feito pelos elaboradores do plano de carreira de 2001; revela, ainda, uma justificativa bem oportuna para essas horas: os limites impostos pela Lei de Responsabilidade Fiscal (Lei Complementar $n^{\circ}$ 101, de 4 de maio de 2000). A solução que quase sempre surge para evitar a elevação da folha é o descumprimento do plano de carreira.

\section{Por que não implementar o valor do piso no plano de 2001?}

A legislação insistentemente tem estabelecido prazos para que os Estados, o Distrito Federal e os Municípios implantem seus Planos de Carreira e Remuneração dos profissionais do Magistério (Lei 9.424/1996) ou profissionais da Educação Básica (Lei $\left.n^{\circ} 11.494 / 2007\right)$. Com a edição da Lei $n^{\circ}$ 11.738, de 16 de julho de 2008 (Lei do Piso), um novo prazo foi estabelecido:

Art. $6^{\circ}$ - A União, os Estados, o Distrito Federal e os Municípios deverão elaborar ou adequar seus Planos de Carreira e Remuneração do Magistério até 31 de dezembro de 2009, tendo em vista o cumprimento do piso salarial profissional nacional para os profissionais do magistério público da Educação Básica, conforme disposto no parágrafo único do art. 206 da Constituição Federal. (BRASIL, 2008, grifo nosso).

Os professores da Rede Pública Municipal de Teresina possuem plano de carreira e o município atende a demanda tanto da Lei do Fundef quanto da Lei do Fundeb, bem como da Lei n 11.738/2008 (Lei

8 Nos IDEBs de 2005, 2007 e 2009, a Rede Pública Municipal de Ensino de Teresina, dentre as capitais nordestinas, ficou em primeiro lugar. Considerando as capitais do país, ficou entre as cinco melhores. 
do Piso). Portanto, o município de Teresina não precisaria preocupar-se em atender o prazo de 31 de dezembro para elaborar plano de carreira, porque já o possuía, nem "correr" para adequar seu plano à Lei do Piso no Supremo Tribunal Federal (STF).

Acredita-se que o clima gerado após a publicação das Diretrizes Nacionais para os Novos Planos de Carreira e de Remuneração para o Magistério Público dos Estados, do Distrito Federal e dos Municípios, pelo Conselho Nacional de Educação (CNE), conforme o parecer CNE/ CEB no 9/2009, tenha contribuído para se passar a ideia de que todos os entes federados teriam que elaborar ou adequar seus planos de carreira até 31/12/2009.

Imagina-se que os elaboradores da Lei $\mathrm{n}^{0} 11.738 / 2008$, bem como os conselheiros do CNE, tinham consciência do impacto que causaria a Lei do Piso nos planos de carreira atuais dos entes federados, por isso a presença da palavra adequar/adequação, tanto na Lei do Piso quanto nas referidas Diretrizes Nacionais.

Para avaliar tal impacto, foi utilizado o plano de 2001 do Município de Teresina e nele aplicado o valor do Piso e observado sua repercussão nos salários das classes mais altas. Antes é preciso abrir um parêntese para que se esclareça como se chegou ao valor do Piso para 2009.

Quando da publicação da Lei $\mathrm{n}^{\circ} 11.738 / 2008$, o valor do piso era de $\mathrm{R} \$ 950,00$, para uma jornada de 40h, para os professores no início da carreira e deveria entrar em vigor em $1^{\circ}$ de janeiro de 2008.

Pelo $\$ 2^{\circ}$, do Art. $3^{\circ}$, a partir de 2010, o piso deveria compreender todas vantagens pecuniárias, pagas a qualquer título. A ideia era incorporar todos os abonos e vantagens salariais no vencimento ${ }^{9}$ do professor, a fim de acabar com uma prática muito comum, em todo o país, que congelava o vencimento e dava-se aumento por meio de abonos.

O valor do piso de $\mathrm{R} \$ 950,00$ deveria ser atualizado no ano seguinte, levando em consideração o crescimento do valor anual mínimo por aluno, referente aos anos iniciais do ensino fundamental urbano [...]:

Art. $5^{\circ} \mathrm{O}$ piso [...] será atualizado, anualmente, no

9 Pela Lei no 8.112, de 11/12/90 - RJU, Art. 40. Vencimento é a retribuição pecuniária pelo exercício de cargo público, com valor fixado em lei. Art. 41. Remuneração é o vencimento do cargo efetivo, acrescido das vantagens pecuniárias permanentes estabelecidas em lei. 
mês de janeiro, a partir do ano de 2009.

Parágrafo único. A atualização [...] será calculada utilizando-se o mesmo percentual de crescimento do valor anual mínimo por aluno referente aos anos iniciais do ensino fundamental urbano [...]. (BRASIL, 2008).

O Ministério da Educação (MEC), por meio de consulta à AGU, fixou em R\$1.024,67 o valor do piso salarial profissional nacional para os profissionais do magistério público da educação básica para o ano de $2010^{10}$. Nesse caso, não foi considerado o aumento referente ao ano de 2009, pois o valor de $\mathbf{R} \$ 950,00$ deveria vigorar a partir de janeiro de 2008. Dessa forma, a lei foi descumprida.

De posse do valor do Piso para janeiro de 2010 ( $\mathrm{R} \$ 1.024,67$ ), determinado pelo Governo Federal, foi aplicado esse valor na posição do referido plano de 2001, para o professor Classe A, Nível 1, que corresponde ao início da carreira, conforme estabelece a Lei do Piso. A repercussão da aplicação desse valor na estrutura da carreira elevaria o vencimento mais a regência do professor Classe E, Nível 7, para $\mathrm{R} \$ 4.672,05$, e para a última posição da carreira, professor Classe H, Nível 11 , o vencimento mais a regência seria de $\mathrm{R} \$ 5.935,94$. Valores bem acima do que receberia um professor na última posição do Plano reformulado (R\$3.581,66), Lei Complementar n ${ }^{0}$ 3.951, de 17 de dezembro de 200911.

A partir da repercussão do valor do Piso Nacional $(\mathrm{R} \$ 1.024,67)$ na estrutura salarial do Plano de 2001, foi possível compreender os motivos que levaram os elaboradores da Lei $n^{0} 11.738 / 2008$, bem como os conselheiros do CNE, a colocarem a palavra adequar/adequação, tanto na Lei do Piso quanto nas referidas Diretrizes Nacionais. Também foi possível compreender porque o Município de Teresina preferiu adequar seu plano de cargos e salários, em vigor até dezembro de 2009, ao aprovar a Lei Complementar $n^{\circ} 3.951$, de 17 de dezembro de 2009, que alterou

10 Para chegar a este percentual, a AGU tomou por base a diferença entre o valor efetivo do Fundeb por aluno praticado em 2008 ( $R$ \$1.132,34) e o de 2009 ( $R \$ 1.221,34$ ). A diferença apurada foi de 7,86\%. Com isso, o piso da jornada de 40 horas passou dos $\mathrm{R} \$ 950$ para $\mathrm{R} \$ 1.024,67$ em janeiro de 2010. Dessa forma, o governo não considerou o aumento do ano de 2009, o qual elevaria o valor proposto pela AGU (R\$1.024,67).

11 Valor obtido na Tabela [Anexo II - Enquadramento do pessoal do magistério (vencimento mais GID) e interstício da progressão e promoção] que consta na Lei Complementar $n^{\circ} 3.951 / 2009$, acrescido de $7,5 \%$ referente ao título especialização, para o professor $40 \mathrm{~h}$. 
dispositivos da Lei $\mathrm{n}^{\circ}$ 2.972, de 17 de janeiro de 2001, que “dispõe sobre o Estatuto e o Plano de Cargos e Salários do Magistério Público da Rede de Ensino do Município de Teresina".

Nesse sentido, a tese de Monlevade (2000), escrita há dez anos, ainda serve para analisar o contexto atual, quando afirmava que:

[...] desde o início do assalariamento do professor público via subsídio literário, existe uma tensão valorativa entre "o suficiente para o sustento e o necessário para a qualidade", que puxam para cima e "as limitações do Tesouro, a desimportância do ofício e o número de professores" que puxam para baixo (MONLEVADE, 2000, p. 98).

Esse tipo de atitude, que o Estado tem dispensado ao professores, parece querer se aproximar da concepção taylorista sobre o trabalhador e parece distanciar-se da teoria de Maslow que reconhece a importância do salário e da motivação do trabalhador para melhorar a qualidade de sua produção.

\section{Considerações finais}

Com a publicação da Lei do Piso e das Diretrizes Nacionais para os Novos Planos de Carreira e de Remuneração para o Magistério dos Estados, do Distrito Federal e dos Municípios, criou-se entre os professores da educação básica das redes públicas um clima de esperança e de muita expectativa com vistas ao reconhecimento e à valorização salarial da categoria. Por parte da população, surgiu a esperança de ver a educação pública brasileira ofertada com a qualidade há muito tempo desejada. Qualidade afirmada por Maria Izabel Azevedo Noronha, relatora da proposta das Diretrizes aprovadas pelo CNE na medida em que, a partir daquelas Diretrizes, abria-se "um novo capítulo no processo de construção de uma educação pública inclusiva e de qualidade para todos no nosso país, a partir do reconhecimento e da valorização dos professores, que são a alma de qualquer sistema educacional" (BRASIL, 2009a). A confiante e otimista relatora talvez consiga despertar expectativas positivas em alguns profissionais do magistério público, 
mas não consegue mudar a incredulidade dos pesquisadores da área de financiamento da educação, acostumados a se debruçar sobre novas legislações e sem o prazer de as verem cumpridas, especialmente os artigos que objetivam garantir mais recursos para educação. $\mathrm{O}$ não cumprimento do valor aluno do Fundef, estabelecido em lei, é apenas mais um histórico exemplo. De quem é a culpa? É dos congressistas que aprovam as leis ou do executivo que não as cumpre? Com certeza não é dos esperançosos professores do magistério público. Com certeza também, não se pode atribuir a eles a culpa pela baixa qualidade da educação pública brasileira.

Considerando a saída que o município encontrou para se adequar às demandas da Lei do Piso, pode-se concluir que pensar numa educação de qualidade sem prever recursos adicionais para sua efetivação é simplesmente transferir a responsabilidade para os professores, esperando deles abnegação e sacerdócio. É pensar que todo município brasileiro possui receitas suficientes para pagar bem seus professores. É pensar que a simples elaboração de um novo plano de cargos e salários será suficiente para melhorar o salário dos professores. É pensar que o problema está apenas na relação conflituosa entre professor e secretário de educação. É não perceber que o salário tem sido uma espécie de cabo de guerra que tem como único perdedor a educação da população. 


\section{Referências}

BRASIL. Constituição (1988). Constituição da República Federativa do Brasil, 1988. Disponível em: <http://www.planalto.gov.br/ccivil_03/ constituicao/constitui\%C3\%A7ao.htm>. Acesso em: 20 dez 2010.

. Congresso Nacional. Lei n. 8.112 de 11 de dezembro de 1990. Dispõe sobre o regime jurídico dos servidores públicos civis da União, das autarquias e das fundações públicas federais. Disponível em: <http://www.planalto.gov.br/ccivil_03/Leis/L8112cons.htm>. Acesso em: 20 dez 2010.

. Congresso Nacional. Lei n. 9.394 de 24 de dezembro de 1996a. Lei de Diretrizes e Bases da Educação Nacional. Disponível em: <http://www.planalto.gov.br/ccivil_03/Leis/L9394.htm>. Acesso em: 20 dez. 2010.

. Congresso Nacional. Lei n. 9.424 de 24 de dezembro de 1996b. Dispõe sobre o Fundo de Manutenção e Desenvolvimento do Ensino Fundamental e de Valorização do Magistério, na forma prevista no art. $60, \S 7^{\circ}$, do Ato das Disposições Constitucionais Transitórias, e dá outras providências. Disponível em: <http:/ / www.planalto.gov.br/ ccivil_03/Leis/L9424.htm>. Acesso em: 20 dez 2010.

Congresso Nacional. Lei Complementar n. 101 de 4 de maio de 2000. Estabelece normas de finanças públicas voltadas para a responsabilidade na gestão fiscal e dá outras providências. Disponível em: <http://www.planalto.gov.br/ccivil_03/Leis/LCP/Lcp101. htm>. Acesso em: 20 dez 2010.

. Congresso Nacional. Lei n. 11.494 de 20 de junho de 2007. Regulamenta o Fundo de Manutenção e Desenvolvimento da Educação Básica e de Valorização dos Profissionais da Educação - 
Fundeb. Disponível em: <http://www.planalto.gov.br/ccivil_03/_ Ato2007-2010/2007/Lei/L11494.htm>. Acesso em: 16 abr. 2010.

. Congresso Nacional. Lei $n^{0} 11.738$, de 16 de julho de 2008.

Regulamenta a alínea "e" do inciso III do caput do art. 60 do Ato das Disposições Constitucionais Transitórias, para instituir o piso salarial profissional nacional para os profissionais do magistério público da educação básica. Disponível em: <http:/ / www.planalto.gov.br/ ccivil_03/_Ato2007-2010/2008/Lei/L11738.htm>. Acesso em: 20 dez. 2010.

. Ministério da Educação. Conselho Nacional de Educação. Parecer CNE/CEB $n^{\circ}$ 9/2009 de 02 de abril de 2009a. Proposta das Diretrizes Nacionais para os Planos de Carreira e Remuneração dos Profissionais do Magistério da Educação Básica Pública. Autora: Maria Izabel Azevedo Noronha. Disponível em: <http://portal.mec. gov.br/dmdocuments/pceb009_09.pdf> . Acesso em: 20 dez. 2010.

Ministério da Educação. Conselho Nacional de Educação. Resolução CNE/CEB n 2 de 28 de maio de 2009b. Fixa as Diretrizes Nacionais para os Planos de Carreira e Remuneração dos Profissionais do Magistério da Educação Básica Pública. <http:// portal.mec.gov. $\mathrm{br} /$ dmdocuments/resolucao_cne_ceb002_2009.pdf $>$. Acesso em: 20 dez. 2010.

. Controladoria Geral da União. Fundeb: Orientações para acompanhamento das ações do Fundo de Manutenção e Desenvolvimento da Educação Básica e de Valorização dos Profissionais da Educação. Brasília, 2010. (Coleção Olho Vivo). Disponível em: <http://www.cgu.gov.br/Publicacoes/ CartilhaOlhoVivo/Arquivos/Fundeb.pdf>. Acesso em: 18 dez. 2010.

CASTRO, Maria Helena G. de. Gestão de Recursos Humanos. IES Instituto Superior de Educação do Vale do Juruena: 2010. Disponível 
em: <http:/ / www.ajes.edu.br/arquivos/20081008161751.pdf >. Acesso em: 18 dez 2010.

DAVIES, Nicholas. Fundeb: a redenção de educação básica? Campinas: Autores Associados, 2008. (Polêmicas do nosso tempo).

MONLEVADE, João A. C. de. Valorização salarial dos professores: o papel do Piso Salarial Profissional Nacional como Instrumento de Valorização dos Professores da Educação Básica Pública. 2000. 307f. Tese (Doutorado em Educação) - Faculdade de Educação, Universidade Estadual de Campinas, Campinas. 2000.

MORDUCHOWICZ, Alejandro. La oferta, la demanda y el salario docente. Modelo para armar. PREAL, Série Documentos, n 45 (ISSN 07186002). Chile, 2009.

TERESINA. Lei n ${ }^{\circ} 1.870$ de 02 de dezembro de 1986. Dispõe sobre o Estatuto do Magistério Público de $1^{\circ}$ e $2^{\circ}$ Graus da Rede de Ensino do Município de Teresina. Diário Oficial do Município, Teresina, 05 dez. 1986.

. Lei $n^{0} 2.97$, de 17 de janeiro de 2001. Dispõe sobre o Estatuto e o Plano de Cargos e Salários do Magistério Público da Rede de Ensino do Município de Teresina. Disponível em <http:/ / www.semec. pi.gov.br/Dimon/Arquivos/Leg_Leis/ Arquivo15.pdf>. Acesso em: 22 set. 2010.

. Decreto $\mathrm{n}^{\circ} 6.835$ de 06 de julho de 2006. Regulamenta o art. 19, da Lei ${ }^{\circ}$ 2.972, de 17 de janeiro de 2001, que dispõe sobre o Estatuto e o Plano de Cargos e Salários do Magistério Público da Rede de Ensino do Município de Teresina, alterado pela Lei n ${ }^{\circ} 3.515$, de 19 de maio de 2006. Diário Oficial do Município, Teresina, n. 1.109, 14 jul. 2006, p. 03 e 04. Disponível em <http:/ / www.teresina.pi.gov.br/dom/doc_diario/ DOM1109-1-14072006.pdf>. Acesso em: 22 set. 2010. 
. Lei Complementar n. 3.951 de 17 de dezembro de 2009. Altera

dispositivos da Lei $n^{\circ} 2.972$, de 17 de janeiro de 2001, que dispõe sobre o Estatuto e o Plano de Cargos e Salários do Magistério Público da Rede Ensino do Município de Teresina, e dá outras providências. Disponível em: <http://www.semec.pi.gov.br/ Dimon/Arquivos/ Leg_Leis/semec_3e5d36ddb3.pdf>. Acesso em: 20 dez. 2010.

\title{
Nacional salary floor in public magistery of Teresina city carreer plan
}

\begin{abstract}
In this article, the impact of Floor Salary Law of Public Magistery Plan of Teresina City of 2001 and the strategies used to adequate law and practice are analyzed. There are some theorization about Salary and Career Plans. The characteristics of 2001 Plan are confronted to 1986 Plan. It is applied 2001 salary in Plan and its impact is analyzed. The expenses with payroll grow a lot, in this sense they opted to adequate his Plan, approving Law $3.951 / 2009$. Finally, it was found that laws are not always fulfilled and an education with real quality without additional resources is just an action of responsibility transference to teachers, expecting their abnegation and priesthood. It is thinking that all Brazilian cities have incomes enough to pay teachers very well. It is to pretend an unreal situation that has as main losers population and education.
\end{abstract}

Keywords: Carreer Plan; Education Financing; Floor Salary.

Recebido: 18/01/2012

Aprovado: 18/06/2012 